\title{
Migraine and epilepsy: what value today?
}

\author{
Cinzia Costa ${ }^{1 *}$, Paolo Prontera ${ }^{2}$, Stefano Caproni ${ }^{1}$, Letizia M Cupini ${ }^{3}$, Paola Sarchiellii ${ }^{1}$ Paolo Calabresi ${ }^{1,4}$ \\ From Abstracts from the 1st Joint ANIRCEF-SISC Congress \\ Rome, Italy. 29-31 October 2015
}

More than 100 years of investigation have found that seizures and migraine co-occur in some affected individuals and families, and there is much evidence that these diseases share genetic susceptibility. In particular, in a recent review, the prevalence of migraine in epileptic patients was about $12 \%$ [1]. On the other hand, epilepsy exhibits a prevalence of about $6 \%$ in migraineurs [2]. Moreover, epilepsy has also been reported in patients with familial hemiplegic migraine (FHM). Although few studies showed a prevalence of epilepsy of about $7 \%$ in FHM, currently no conclusive data are available.

Certainly, epilepsy and migraine share common characteristics that the underlying pathophysiology relates to alterations in ion channels or ion transporters. In these episodic functional diseases, in which susceptible brain regions are hyperexcitable, the attacks begin with hypersynchronous neuronal firing [3]. In epilepsy, $\alpha$-amino-3hydroxy-5-methyl-4-isoxazolepropionic acid (AMPA) receptors play a predominant role in mediating the generation and spread of seizure activity whereas in migraine mainly $\mathrm{N}$-methyl-D-aspartate (NMDA) receptors are involved in triggering CSD. However, the nature of the ionic conductance changes leading to the massive but transitory neuronal depolarization underlying CSD has not yet been define [4].

Genetically determined dysfunction of ion transporters seems to point at a common underlying mechanism for both paroxysmal disorders. In the last two decades the mutations in the ion transportation genes CACNA1A, $A T P 1 A 2$ and $S C N 1 A$ have been identified for FHM. Conversely, only a few $C A C N A 1 A$ and $A T P 1 A 2$ mutations have been reported in patients with sporadic hemiplegic migraine (SHM). These cases can be caused by a de novo mutation or by inheritance of a gene mutation from asymptomatic carrier and are usually characterized by early-onset, severe and complex disorders.

Certainly, genetic analysis can provide greater insight into the potential causes of both disorders and it could contribute to better treatment choices.

\section{Authors' details}

${ }^{1}$ Clinica Neurologica, Università di Perugia, Ospedale S. Maria della Misericordia, Perugia, Italy. ${ }^{2}$ Sezione di Genetica Medica, Dipartimento di Medicina Clinica e Sperimentale, Azienda Ospedaliera e Università di Perugia, Perugia, Italy. ${ }^{3}$ Centro Cefalee, UOC Neurologia, Ospedale S. Eugenio, Rome, Italy. ${ }^{4}$ Fondazione Santa Lucia, IRCCS, Rome, Italy.

\section{Published: 28 September 2015}

\section{References}

1. Selassie AW, Wilson DA, Martz GU, Smith GG, Wagner JL, Wannamaker BB: Epilepsy beyond seizure: a population-based study of comorbidities. Epilepsy Behav 2014, 32:42-48.

2. Bellini B, Arruda M, Cescut A, Saulle C, Persico A, Carotenuto M, Gatta M, Nacinovich R, Piazza FP, Termine C, Tozzi E, Lucchese F, Guidetti V: Headache and comorbidity in children and adolescents. J Headache Pain 2013, 14:79.

3. Rogawski MA: Common pathophysiologic mechanisms in migraine and epilepsy. Arch Neurol 2008, 65(6):709-14.

4. Rogawski MA: Migraine and epilepsy-shared mechanisms within the family of episodic disorders. In Jasper's Basic Mechanisms of the Epilepsies. 4 edition. Bethesda (MD): National Center for Biotechnology Information (US);Noebels JL, Avoli M, Rogawski MA, Olsen RW, Delgado-Escueta AV 2012:

doi:10.1186/1129-2377-16-S1-A44

Cite this article as: Costa et al.: Migraine and epilepsy: what value today? The Journal of Headache and Pain 2015 16(Suppl 1):A44.

\footnotetext{
* Correspondence: cinzia.costa@unipg.it

${ }^{1}$ Clinica Neurologica, Università di Perugia, Ospedale S. Maria della

Misericordia, Perugia, Italy

Full list of author information is available at the end of the article
} original work is properly cited. The Creative Commons Public Domain Dedication waiver (http://creativecommons.org/publicdomain/ zero/1.0/) applies to the data made available in this article, unless otherwise stated. 